\title{
Missed Opportunity for Family Planning among Obstetric Fistula Clients in North-Western Nigeria
}

\author{
Alayande $\mathrm{A}^{1 *}$, Ikwe $\mathrm{H}^{1}$, Nuhu $\mathrm{IA}^{2}$ and Umeh $\mathrm{GC}^{3}$ \\ ${ }_{1}^{1}$ United Nations Population Fund, Nigeria \\ ${ }^{2}$ Igbinedon University, Nigeria \\ ${ }^{3}$ World Health Organisation Kaduna, Nigeria
}

*Corresponding author: Audu Alayande, United Nations Population Fund, 1 Alimi

Road, off Independent Way, Kaduna, Nigeria, Tel: 08035368020; E-mail: alayande@unfpa.org

\section{Research Article \\ Volume 1 Issue 1}

Received Date: October 06, 2017

Published Date: October 30, 2017

DOI: $10.23880 /$ whsj-16000103

\section{Abstract}

Background: For Nigeria to attain a Contraceptive Prevalence Rate (CPR) of 36\% in 2018 as committed by the Federal Government at the London 2012 summit, Family Planning (FP) services must be provided to all eligible couples at every contact with the health system, including the Obstetric fistula (OF) units. In Nigeria, about 20,000 women develop OF annually for which access to FP services will prevent recurrence of OF and increase the FP utilization. This study therefore assessed the prevalence of missed opportunities for FP, its trend amongst repaired OF clients, the possible causes and suggested recommendations.

Methods: This cross-sectional descriptive study was conducted in two OF and FP units of hospitals in Zaria and Sokoto. Records of FP for the 1,015 OF clients admitted from 2011-2015 were extracted and analyzed on SPSS version 20. Also questionnaire survey were applied and analyzed on excel for all the 8 health workers and 18 repaired OF clients available in the units during the study period.

Results: Seventy percent of the 1,015 OF repaired by the two units did not take a FP method post repair.. The main reasons given by OF service providers for these missed opportunities were the desire for more children by $\mathrm{OF}$ client having lost the index one, inadequate FP training for OF staff and client ignorance. Suggestions by the OF service providers for improvement include improved client counselling, quality FP services and information, client sensitization, training of staff on FP services and balanced counselling.

Conclusion: The implementation of the above suggestions by stakeholders, reinforced with appropriate IEC strategy will reverse these missed opportunities.

Keywords: Missed Opportunity; Family Planning; Obstetric Fistula; Contraceptive Prevalence Rate 


\section{Introduction}

Although Family planning (FP) is a human right that is central to gender equality and poverty reduction, yet about 225 million women have unmet need for FP which is against the Sustainable Development Goal slogan of "leaving no one behind [1,2]. An analysis of postpartum women across 21 low and middle income countries revealed that $61 \%$ of them have an unmet need for FP [3]. Despite progress made in CPR, the unmet need for FP in Nigeria is $16.1 \%$, with Sokoto and Kaduna States reporting $7.5 \%$ and $5.8 \%$, respectively [4]. One of the reasons for the low CPR as reported in the 2013 Nigeria Demographic and Health Survey (2013 NDHS) was that only $1.2 \%$ and $6.1 \%$ of women in Sokoto and Kaduna States, respectively visited a health facility in the past 12 months before the survey to discuss FP [4]. Table 1 shows the reproductive health Indices for Kaduna and Sokoto States (NDHS 2013).

\begin{tabular}{|c|c|c|c|}
\hline Reproductive health indicator & Kaduna State & Sokoto State & National \\
\hline Contraceptive prevalence rate (\%) & 20 & 1 & 15 \\
\hline Unmet need for family planning (\%) & 5.8 & 7.5 & 16 \\
\hline Antenatal clinic attendance rate (\%) & 5.8 & 20.3 & 66.1 \\
\hline Skilled birth attendant at delivery (\%) & 35.5 & 5.4 & 38.1 \\
\hline Health facility delivery (\%) & 32.4 & 4.7 & 35.8 \\
\hline
\end{tabular}

Table 1: Reproductive Health Indices: Kaduna and Sokoto States versus National data (NDHS 2013).

The Nigeria Government has set a target to achieve $36 \%$ CPR by 2018 [5] from its current value of 15 [4]. This drive requires more concerted interventions to increase access and utilization in States within the Northern geopolitical zones where CPR ranges between 3-16\% for all methods [3]. Specifically, States like Kaduna and Sokoto are expected to attain CPR of $46.5 \%$ and $20 \%$ by 2018 from its present $20 \%$ and $1 \%$, respectively [6]. This requires provision of FP services and information to all women of reproductive age at every contact with the health system including those in the OF repair units. If more effort is put towards addressing the huge unmet need and reduce missed opportunities, this will contribute to the reduction of the high maternal deaths and OF [7].

Annually about 20,000 women develop OF in Nigeria [8]. The root cause of $O F$ is a lack of sexual and reproductive rights for women [9]. Therefore in line with the principles of equity and non-discrimination, the London Family Planning (FP2020) summit emphasized improved access especially for marginalized women, those who have had fistula repair, who are hard to reach and who may in addition face financial and social barrier that will prevent them from accessing FP services. Therefore, each contact of OF client with health facility for management is an opportunity to provide them with the full range of Reproductive Health (RH) services and information including FP.

OF occurs as a result of prolonged, obstructed labour due to lack of adequate medical care, notably timely access to a life-saving emergency caesarean section. Although it is a devastating medical condition, it is mostly preventable and treatable. Globally over 2 million women and girls suffer from OF [10]. This high number reflects underlying failure to tackle broader health, socio-economic and gender inequities as well as child marriage and teenage pregnancy.

Globally about 20,000 women have fistula repairs annually but another 50,000 new cases occur annually leaving an annual backlog of about 30,000 [10]. FP is a proven strategy to reduce maternal morbidity and mortality [11]. Also it is the best strategy to reducing fistula cases among women of reproductive age in Nigeria [11]. It is therefore an integral part of $\mathrm{OF}$ prevention [12]. Also in order to achieve complete healing, most post-repair OF patients are advised to abstain from sex for three months or more [13]. Thus the use of a FP method will enable these women to resume sexual activities after the abstinence period of 3-6 months without the risk of another pregnancy before healing $[6,13,14]$. It will also protect a repaired OF, prevent breakdown and recurrence by delaying pregnancy [13].

Globally, there is high awareness of modern contraception among OF patients but only few actually utilize any modern contraceptive method after surgical repair. A study in South East Nigeria reported 95.7\% awareness but only $37.2 \%$ utilization of contraceptives after OF surgery [14]. Reasons adduced for the low utilization after OF surgical repairs ranges from socioeconomic grounds, myths, religious and cultural beliefs [14].

Also it is sometimes assumed that women with repaired OF are not interested in FP services because they might have lost a baby in the preceding complication [11]. On the contrary, studies indicate that 
they are interested in using FP if they know about it during their post-operative period [11]. More than $76 \%$ of OF patients in four Kenya referral centers expressed their willingness to access FP services after the fistula repair [15]. Enabling these women to access FP services can greatly reduce their chances of developing new OF or dehiscence because it gives them more control over the "when and how" of their pregnancies [9].

A 'missed opportunity' is a chance to do or accomplish something that you did not take advantage of [16]. Therefore missed opportunity for FP is an opportunity for FP service and information that was missed at the OF or FP units. A well integrated FP-fistula service will help to ensure that FP is an integral part of OF treatment, not an additive service $[13,17]$. This integrated approach has been found to improve the uptake of FP methods by OF clients [12].

Additionally, FP counseling will also help women who want to achieve successful pregnancy to increase their chances through increased fertility awareness [13]. Therefore, adequate post repair FP information will empower the women to make their own reproductive decisions and respects their rights to reproductive self-determination [13]. Several country reports indicated between $60-70 \%$ of OF clients counseled choose a FP method [12].

It was therefore the aim of this study to evaluate the missed opportunity for FP services and information by post repaired OF client in two major fistula centers in North Western Nigeria. The study objectives were to assess the extent of missed opportunity for FP service amongst repaired OF clients in the centers, to determine the level of counseling on FP information amongst the repaired OF clients and to identify ways of reducing missed opportunity to improve FP utilization by repaired OF clients.

\section{Methodology}

The cities of Zaria and Sokoto are located in Kaduna and Sokoto States, respectively in Northwest Nigeria. These States have strong male dominated traditional feudal system with stronghold at the community level despite the existence of modern democratic governance system. Most aspects of the society are male dominated; politics, economy, commerce, education, culture and religion [18]. The average literacy rate in these States is $45 \%$ while about $60 \%$ of the population live below the poverty line $[19,20]$.

There is one public hospital in each of the States with a major Obstetric Fistula (OF) unit - Gambo Sawaba General Hospital (GSGH) in Zaria, Kaduna State and
Maryam Abacha Women and Children's Hospital (MAWCH) in Sokoto North, Sokoto State. The former is about 78 kilometers from Kaduna town the State capital [21]. The OF unit in Zaria has repaired over 1,500 OF from 1996 till date with a success rate of over $90 \%$. All repaired OF clients are routinely referred to the hospital's FP unit for counseling and FP services. Maryam Abacha Women and Children's Hospital (MAWCH) in Sokoto State offers comprehensive emergency obstetric care and FP services [22]. Record showed that the unit repaired 492 cases between 2013 and 2015. This study was conducted in the OF and FP units of GSGH in Zaria, Kaduna State and MAWCH in Sokoto, Sokoto State.

This was a descriptive cross-sectional study using quantitative and qualitative data collection methods on FP services and information from the OF and FP units of GSGH Zaria and MAWCH Sokoto.

The quantitative data collection was a desk review which entails collection of all FP and OF registers used in the year 2011 to 2015 from the respective units. The data capturing template was designed on SPSS 20 to include all the indices in the National FP register and the health facility OF registers like the clients sociodemographic characteristics, obstetrics history, OF repairs and utilization of FP. All available FP service utilization data for the period were extracted onto this data template by a member of the study team. Then the list of all OF patients admitted for repair during the five year period $(2011$ - 2015) were extracted from the OF register of which those of them that accessed FP services after their successful repair were identified in the corresponding FP register. A total of $1015 \mathrm{OF}$ clients were registered for repair but only 305 of them registered for FP services in the 5 years study period in the two units as follows; MAWCH Sokoto has 562 registered repaired OF clients of which 169 registered for FP, while GSGH Zaria has 453 OF clients of which 136 registered for FP.

The qualitative study was conducted using a questionnaire instrument. This consist of closed and open ended questions ranging from socio-demographic data, information provided by the health care workers during counseling, information of FP utilization by OF clients in the units, their training needs and challenges related to FP service provision. In addition, the questionnaire for the repaired OF clients include their educational, obstetric and surgical history, counseling experience, their knowledge, attitude, practice and behavior on the use of FP after OF repair. The instrument was pretested among repaired OF clients and health workers at the Federation of Muslim Women Association clinic in Kaduna. Required adjustment was 
made to be able to elicit the required responses which were guided by the qualitative data in the FP and OF registers.

All available OF clients (on post-operative admission or follow-up visits) and health workers presently working in the two units during the study period of July - November 2016 were selected to participate in the study. They were all separately interviewed face-to-face by a trained interviewer after informed consent was obtained. A total of 8 health workers available in the two units and 18 repaired OF clients that were either on admission or visited the units during the data capturing period of July to November, 2016 were interviewed. The data from the interviews were collated on Microsoft Excel sheets.

Approval for the study protocols were given by the respective Departments of Planning Research and Statistics of the States Ministries of Health in Sokoto and Kaduna. The facility Directors gave permission to review fistula clients' records including the interviews of its health providers and clients. The interview took place in the office of the nurse-in-charge of the OF units. Each of the respondents gave their consent prior to the interview after due explanation of the purpose, process and conditions as stated on the questionnaire by the interviewer.

All the quantitative data were analyzed using the SPSS 20 software to generate summary statistics, tables, range, per cent and charts. The prevalence of missed opportunity for FP was estimated as the number of repaired OF client who has missed opportunity for FP service divided by the total number of repaired OF client in the respective units. The qualitative data were analysed on separate Excel sheets to generate basic statistical indices of percentages, means and total summation of responses.

\section{Results}

\section{Evidence in Family Planning and Obstetric Fistula Registers}

Although the majority of the 1015 OF clients were from Kaduna and Sokoto States, $10 \%$ came from the neighbouring States and across the nation's border from Niger and Chad Republics. Their ages ranged from 1348 years with a mean of 22.7 years. Their parity ranged from $0-12$ with a median of 1 . About $13 \%$ of them either have no child alive or had more than 4 parity. All the $\mathrm{OF}$ client had counselling sessions on FP.

The number of repaired OF client that did not use any FP service annually is indicated in Table 2 below. The number of repaired OF client that did not use FP service had been on the increase in Sokoto while the reverse is the case in Zaria. Nevertheless, the average missed opportunities for the 5 year period are the same for the two units which stand at $70 \%$.

\begin{tabular}{|c|c|c|c|c|}
\hline Variable & \multicolumn{4}{|c|}{ Sokoto } \\
\hline Year & $\begin{array}{c}\text { Number of } \\
\text { obstetric fistula } \\
\text { repaired }\end{array}$ & $\begin{array}{l}\text { Number of repaired obstetric fistula } \\
\text { that had family planning }\end{array}$ & $\begin{array}{c}\text { Number of repaired } \\
\text { obstetric fistula that } \\
\text { missed family planning }\end{array}$ & $\begin{array}{c}\text { Family planning missed } \\
\text { opportunity rate }(\%)\end{array}$ \\
\hline 2011 & 27 & 27 & 0 & 0 \\
\hline 2012 & 43 & 41 & 2 & 5 \\
\hline 2013 & 131 & 29 & 102 & 78 \\
\hline 2014 & 182 & 52 & 130 & 71 \\
\hline 2015 & 179 & 20 & 159 & 89 \\
\hline TOTAL & 562 & 169 & 393 & 70 \\
\hline \multicolumn{5}{|c|}{ Zaria } \\
\hline 2011 & 85 & 21 & 64 & 75 \\
\hline 2012 & 64 & 27 & 37 & 58 \\
\hline 2013 & 94 & 20 & 74 & 79 \\
\hline 2014 & 114 & 37 & 77 & 68 \\
\hline 2015 & 96 & 31 & 65 & 68 \\
\hline TOTAL & 453 & 136 & 317 & 70 \\
\hline
\end{tabular}

Table 2: Uptake and missed opportunity for family planning among repaired obstetric fistula clients in Sokoto and Zaria between 2011 and 2015.

\section{Report from Obstetric Fistula Care Providers}

The information gathered with the questionnaire that was applied to all 8 health workers in the two units indicated that $88 \%$ of them counselled OF patient pre and post-operative and then referred them to FP clinic on discharge (Table 3). The OF workers reported an 
average FP awareness of $85 \%$ for the repaired OF clients and an estimated FP utilization rate of between 5
- $80 \%$ with an average of $71 \%$.

\begin{tabular}{|c|c|c|c|}
\hline Questions asked at the interview & Types of responses & Frequency & $\begin{array}{l}\text { Percentage } \\
(\%)\end{array}$ \\
\hline \multirow{2}{*}{$\begin{array}{l}\text { What are the procedures for your repaired fistula clients to } \\
\text { access family planning counseling and services? }\end{array}$} & By referral & 7 & \begin{tabular}{|l|}
87.5 \\
\end{tabular} \\
\hline & Counseling & 4 & 50 \\
\hline \multirow{2}{*}{$\begin{array}{l}\text { Do you counsel repaired obstetric fistula patients before and } \\
\text { after repairs? }\end{array}$} & Yes & 7 & 87.5 \\
\hline & No & 1 & 12.5 \\
\hline \multirow{9}{*}{$\begin{array}{l}\text { Kindly share with us some of the information provided to the } \\
\text { clients during counseling. }\end{array}$} & $\begin{array}{l}\text { Types of family } \\
\text { planning methods }\end{array}$ & 1 & 12.5 \\
\hline & $\begin{array}{l}\text { Benefits of family } \\
\text { planning }\end{array}$ & 2 & 25 \\
\hline & $\begin{array}{l}\text { Need to delay } \\
\text { pregnancy for } 6-12 \\
\text { months after repairs }\end{array}$ & 4 & 50 \\
\hline & $\begin{array}{l}\text { Need to attend family } \\
\text { planning clinic }\end{array}$ & 5 & 62.5 \\
\hline & $\begin{array}{c}\text { Delay sexual } \\
\text { intercourse for } 6 \\
\text { months after repairs }\end{array}$ & 5 & 62.5 \\
\hline & Take plenty of water & 1 & 12.5 \\
\hline & Reduce hard work & 1 & 12.5 \\
\hline & $\begin{array}{l}\text { Attend ante natal clinic } \\
\text { when pregnant }\end{array}$ & 1 & 12.5 \\
\hline & $\begin{array}{l}\text { Next delivery should be } \\
\text { by cesarean section }\end{array}$ & 1 & 12.5 \\
\hline \multirow{4}{*}{$\begin{array}{l}\text { How can the utilization of family planning services by } \\
\text { repaired obstetric fistula patients be improved in this } \\
\text { environment? }\end{array}$} & $\begin{array}{l}\text { Allow freedom of choice } \\
\text { of family planning } \\
\text { method }\end{array}$ & 1 & 12.5 \\
\hline & Individual counseling & 4 & 50 \\
\hline & $\begin{array}{c}\text { Community } \\
\text { sensitization } \\
\end{array}$ & 5 & 62.5 \\
\hline & $\begin{array}{l}\text { Training of family } \\
\text { planning providers }\end{array}$ & 2 & 25 \\
\hline \multirow{5}{*}{$\begin{array}{l}\text { As health workers, what are the challenges encountered in } \\
\text { family planning service provision for repaired obstetric fistula } \\
\text { patients? }\end{array}$} & $\begin{array}{l}\text { Misconceptions on } \\
\text { family planning by } \\
\text { clients }\end{array}$ & 1 & 12.5 \\
\hline & Inadequate manpower & 2 & 25 \\
\hline & $\begin{array}{l}\text { Low awareness of } \\
\text { family planning }\end{array}$ & 1 & 12.5 \\
\hline & $\begin{array}{l}\text { Lack training on family } \\
\text { planning }\end{array}$ & 5 & 62.5 \\
\hline & $\begin{array}{l}\text { Payment by clients for } \\
\text { other family planning } \\
\text { consumables }\end{array}$ & 1 & 12.5 \\
\hline
\end{tabular}

Table 3: Results of the interviews conducted for health workers in obstetric fistula centres of Sokoto and Zaria (n=8).

The types of information provided during counseling includes the FP methods available; health benefits of FP to mother and baby; importance of child spacing to regain health after post repair elective cesarean section (ELCS); advice not to get pregnant in next 6months after repair; the need to attend FP clinic; abstinence from sex till after 6months and not to get pregnant until after 12 months post repair; clients should drink plenty of water; clients should reduce hard work; the need to 
attend ANC when pregnant; and that the next delivery should be by ELCS.

Only one health worker believed that FP uptake by OF client is not low, but most believed it was low because the $\mathrm{OF}$ client wants more children having lost the first one, the lack of FP training by OF clinic staff, ignorance by OF client, their religious / traditional belief and outright rejection of FP by OF clients. The major challenges mentioned by OF unit staff are lack of training on FP service provision, client ignorance on FP, inadequate manpower and some payment by client for consumables.

\section{Report from Obstetric Fistula Clients}

The OF clients interviewed were mostly uneducated
(61\% have no any form of formal education, $23 \%$ attended up to primary school while 17\% had Arabic education) with an average parity of 3.6 per woman. Some $88 \%$ and $40 \%$ of clients in Sokoto and Zaria respectively had no child alive. The average frequency of OF repairs was 1.9 and 1.4 per client in Sokoto and Zaria respectively. Between $12.5 \%$ to $60 \%$ of the OF clients were counseled on FP and the importance of child spacing (Table 4) while their awareness of FP is between $70-87 \%$ in the two units. None of the post repaired OF client in Sokoto liked or utilized a FP method but $75 \%$ of them think FP is useful. Conversely about $70 \%$ of the respondents in Zaria liked FP but only $60 \%$ used a method after OF repair. Some reasons given for not using any FP method includes absence of a child alive, being divorced, being postmenopausal or was not informed about FP.

\begin{tabular}{|c|c|c|c|c|c|}
\hline \multirow[b]{2}{*}{$\begin{array}{l}\text { Questions asked at the } \\
\text { interview }\end{array}$} & \multirow[b]{2}{*}{ Types of responses } & \multicolumn{2}{|c|}{ Sokoto $\mathrm{n}=8$} & \multicolumn{2}{|c|}{ Zaria $n=10$} \\
\hline & & Frequency & $\begin{array}{c}\text { Percentage } \\
(\%)\end{array}$ & Frequency & $\begin{array}{c}\text { Percentage } \\
\text { (\%) }\end{array}$ \\
\hline \multirow{2}{*}{$\begin{array}{l}\text { Did you commence } \\
\text { family planning after the } \\
\text { obstetric fistula repair? }\end{array}$} & Yes & 0 & 0 & 6 & 60 \\
\hline & No & 8 & 100 & 4 & 40 \\
\hline \multirow{6}{*}{$\begin{array}{c}\text { If no to above, state the } \\
\text { reasons. }\end{array}$} & I did not demand for family planning & 0 & 0 & 1 & 10 \\
\hline & I have no child alive & 3 & 37.5 & 2 & 20 \\
\hline & Lack knowledge of family planning & 1 & 12.5 & 1 & 10 \\
\hline & $\begin{array}{l}\text { Am divorced, so no need for family } \\
\text { planning }\end{array}$ & 2 & 25 & 0 & 0 \\
\hline & I have no reason. I relies on God & 1 & 12.5 & 0 & 0 \\
\hline & No response & 1 & 12.5 & 6 & 60 \\
\hline \multirow{3}{*}{$\begin{array}{l}\text { Were you counseled on } \\
\text { the use of family } \\
\text { planning following the } \\
\text { successful repair? }\end{array}$} & Yes & 1 & 12.5 & 6 & 60 \\
\hline & No & 6 & 75 & 4 & 40 \\
\hline & Don't know & 1 & 12.5 & 0 & 0 \\
\hline \multirow{6}{*}{$\begin{array}{c}\text { What type of } \\
\text { counseling information } \\
\text { was provided? }\end{array}$} & Not counseled & 5 & 62.5 & 0 & 0 \\
\hline & When to commence family planning & 1 & 12.2 & 0 & 0 \\
\hline & Importance of family planning & 0 & 0 & 1 & 10 \\
\hline & Types of contraceptives & 0 & 0 & 4 & 40 \\
\hline & Cannot remember & 0 & 0 & 4 & 40 \\
\hline & No response & 2 & 25 & 1 & 10 \\
\hline \multirow{5}{*}{$\begin{array}{l}\text { What are your } \\
\text { suggestions for } \\
\text { improvement of family } \\
\text { planning utilization? }\end{array}$} & $\begin{array}{c}\text { Provide preoperative counseling on } \\
\text { family planning }\end{array}$ & 0 & 0 & 4 & 40 \\
\hline & Allay fears and misconceptions & 0 & 0 & 1 & 10 \\
\hline & $\begin{array}{l}\text { Provide immediate postoperative } \\
\text { family planning services }\end{array}$ & 2 & 25 & 0 & 0 \\
\hline & $\begin{array}{l}\text { Provide more information materials } \\
\text { on family planning for women }\end{array}$ & 5 & 62.5 & 0 & 0 \\
\hline & No response & 3 & 37.5 & 5 & 50 \\
\hline
\end{tabular}

Table 4: Results of the interviews conducted for obstetric fistula clients in Sokoto and Zaria obstetric fistula centres $(\mathrm{n}=18)$. 


\section{Suggestions to Reduce Missed Opportunities}

The various recommendations made by OF providers and $\mathrm{OF}$ clients on how to reduce missed opportunities are as indicated below in Figures $1 \& 2$.

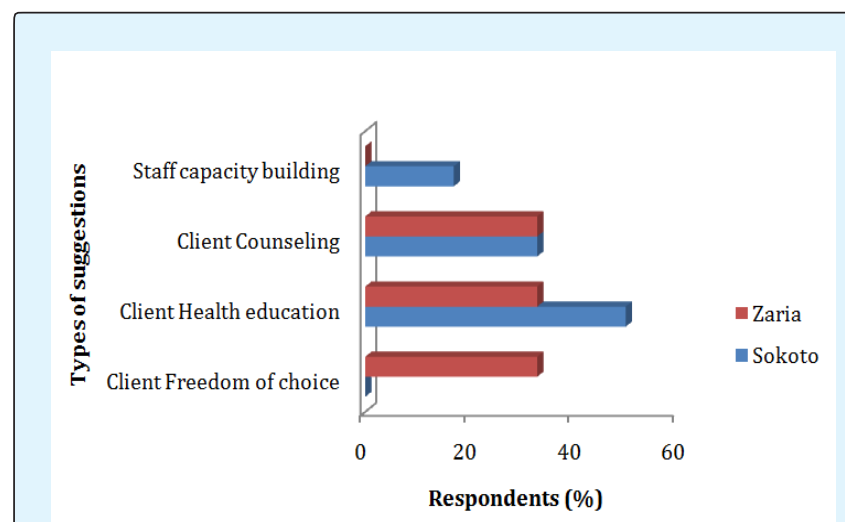

Figure 1: Suggestions by OF provider to reduce missed opportunity.

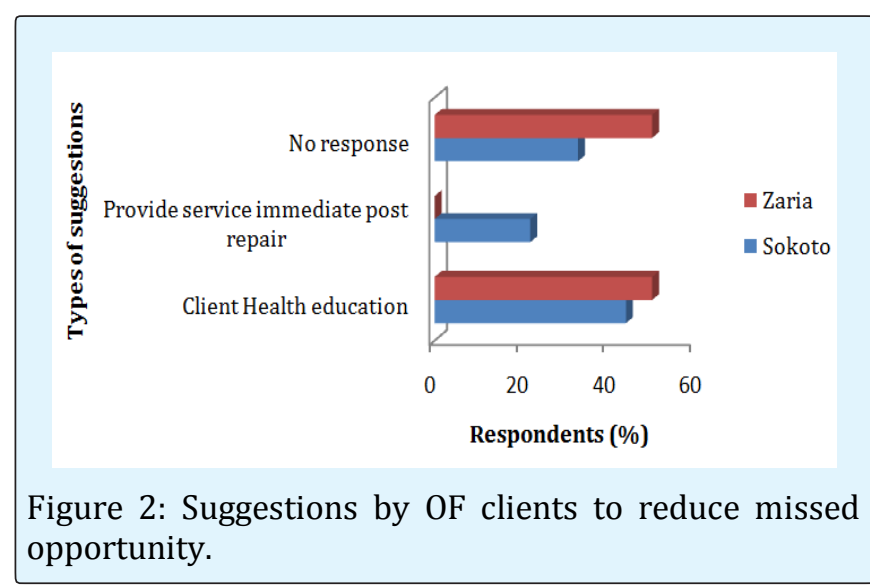

The main suggestions by providers in Zaria are freedom of choice (33\%), health education (33\%) and counselling (33\%) while providers in Sokoto mainly suggested health education (50\%) and counselling $(33 \%)$. The need for capacity building was not mentioned by the OF providers in Zaria.

The only OF clients' suggestions for reducing missed opportunity of FP utilization in Zaria is health education (50\%), while those in Sokoto suggested health education (44\%) and immediate post operative service provision (22\%).

Both the OF providers and clients were in agreement on the need for more health education sessions for $\mathrm{OF}$ clients to improve FP utilization and reduce missed opportunities. Health education includes all forms of awareness creation and sensitization on FP services and information.

\section{Discussion}

The study established the occurrence of missed opportunity for FP at the OF units as evidenced in the OF register, FP register and corroborated by the interviews with the OF providers and their clients. The latter also provided recommendations on how to reduce missed opportunity.

Some $10 \%$ of the OF clients came from outside the States hosting the OF units. This is due to scarcity of facilities and expertise in neighboring states. Their ages ranged from 13-48 years with an average of 22.7 years. This range showed that the occurrence of OF cuts across all women of child bearing age especially where there is poor access to emergency obstetric care services. Similar average age was reported from a study of four OF referral centres in Kenya [15], though another study of $\mathrm{OF}$ in five developing countries including Nigeria reported a slightly higher average age of 25 years with a range of 20-35 years [23]. That about a quarter (19.3\%) of them were under 18 years of age again bring to fore the hazard of early marriage especially in poor health resource settings.

The OF clients had a median parity of 1.0 which is lower than was reported from other studies [23] but confirmed the fact that OF may occur amongst both nulligravida and multigravida women as long as timely emergency obstetric care is not provided as and when needed. Also most of the OF survivors had lost their child due to prolonged labour.

Applying one of the indicators of OF reintegration as recommended by Measures Evaluation, 'percentage of women who have been treated for OF who received FP or birth spacing counselling' [24], the annual prevalence of FP utilization by repaired OF patient ranged from $100 \%$ in 2011 to $11.2 \%$ in 2015 in the Sokoto unit, while the OF unit in Zaria reported an annual prevalence range of $24.7 \%$ in 2011 to $42.2 \%$ in 2012 . Thus according to the facility registers, this indicates an increase in missed opportunity in Sokoto and a decrease of the same in Zaria over the years giving an average of $70 \%$ missed opportunity (Table 2). This is slightly higher than findings from South East Nigeria [14] and much more than reported from other studies $[12,23]$. This may not be unrelated to factors like incomplete documentation of services and poor data storage at the FP units. In this study there were missing OF data from January to June 2011 and May to December 2015 in the Sokoto centre. The declining trend in Sokoto and the improvement in Zaria aligned with the reports of the last two National Demographic Health Surveys (NDHS) for those States [4]. Nevertheless the result clarifies the assumptions that 
women have neither interest in nor need for FP after OF repair because of loss of the baby [12]. On the contrary formal counseling programmes has shown that many clients are open to the idea of FP and willing to practice if given the choice and opportunity [25].

Discussion with OF care providers and their clients showed that implant and injectable contraceptives are commonly preferred methods. The preference for the Long Acting Reversible Contraceptives (LARC) may not be unrelated to the advancement in FP technology and the promotion of its use which was facilitated by the removal of user-fees in Nigeria. The recommendations on FP method choice for OF client depend on their plans for child spacing or limiting. The pill, Standard days method, Male and Female condoms are recommended for those who wants to have a baby soon after healing [26]. The injectables are better suited for those who want to delay first pregnancy after fistula repair and healing, while implants and IUDs are recommended for those who want to delay pregnancy for a long period or may not want any more children [26]. The male and female sterilizations are for those who do not want any children in the future [25].

The method choice also brings to bear the question on quality of FP counseling provided at the centres in terms of neutrality, clarity of information, provider bias and freedom of choice. A report once confirmed that $25 \%$ of FP providers did not help the client consider her options or reconfirms her choice during counseling [12]. Limitation of method choice has been a known hindrance to the uptake of FP by willing couples which further compound the high unmet need.

The eight OF providers that were available in the OF units said they were not trained on FP service. Nevertheless $88 \%$ of them provided counseling service for OF patient pre and post-operative and then referred them to the FP units on discharge. A previous study confirmed that $90 \%$ of the women were counseled for FP during their stay in the OF centre which is in agreement with the present study [23]. Sessions on FP counseling have always been part of the overall counseling training offered to staff in fistula units $[11,12,23,25]$. The deficiency is the lack of training on FP service provision skill which may not be unrelated to the existence of a FP unit within the hospital premises. Despite all efforts, the OF providers think the uptake of FP by repaired OF client is between $5-80 \%$, at an average of $71 \%$ and a missed opportunity of between $20-95 \%$.

The types of information shared during counseling includes the FP methods available; health benefits of FP to mother and baby; importance of child spacing to regain health after post repair ELCS; caution not to get pregnant in the next 6months; the need to attend FP clinic; abstinence from sex till after 6 months and not to get pregnant till after 12 months; need for clients to drink plenty of water; need to reduce hard work; advise to attend Ante Natal Clinic (ANC) when pregnant; and conduct of ELCS in next pregnancy. All these is to allow for healing before the next pregnancy while she is on child spacing method $[11,25]$. The average OF provider believed that at least $85 \%$ of the OF client were aware of FP which is almost about the same level (95.7\%) of awareness reported from a 2015 study of post OF repaired client from South East Nigeria [14]. This alluded to the fact that routine FP counseling still takes place in these centers. Therefore the problem of missed opportunity for FP among the OF client is that of practice but not of knowledge. It is also pertinent to examine the quality of the counseling sessions as some study reported that some of the FP providers were uncomfortable discussing sexuality and clients' relationships with partners; several lacked different types of communications skills, such as being able to ask open-ended questions, paraphrase the clients' responses and questions, or use simple language; some neither thanked the client at the end of the session; nor explore the woman's feelings [12]. Another study reported only $13 \%$ of women re-visited for FP services in response to counseling while $25 \%$ said the discussion had no impact on them [27].

Most (87.5\%) OF provider believed that the FP uptake was not optimal because the OF client wants more children having lost the first one, the lack of training on FP by OF clinic staff, ignorance by OF client, their religious / traditional belief and outright rejection of FP by OF clients. Preference for large family size, low awareness of beneficial reproductive health services and the overbearing influence of religious and traditional leaders has been the bane of poor maternal health indices in the study area. Some of the root causes include low education and poverty among women.

The OF staff suggestions for reduction of missed opportunity of FP utilization amongst OF client includes clients sensitization, improve counseling and staff training. Training skills in balanced counseling and twoway referral should be provided to ensure the OF clients freedom of choice. Documented options for the promotion of FP service utilization by repaired OF clients include referrals by health workers in fistula clinics to outside FP services, offering of initial counseling for FP services within the same institution or to provide integrated care for both OF and FP [30]. An integrated care approach is presently the preferred option in the spirit of universal health coverage. This will also reduce the loss of client during referrals. Also 
previous studies have recommended that staff already working with fistula clients should be further trained to provide FP services [30]. The latter will lead to improvement in the quality of FP information and services [31] and should be facilitated by providers who have experience in providing FP [28].

The summary response to the questionnaire by the 18 OF clients is as indicated in Table 4 . About $61 \%$ have no formal education which is much higher than previously reported from other countries $[14,15]$. This interrelationship between the triad of poverty, illiteracy and diseases has long been established in public health. Although $75 \%$ of OF client in Sokoto appreciates the usefulness of FP but none of them uses any method thus further reinforcing the difference between knowledge, attitude and practice especially within the milieu of a hierarchical society.

The reasons given in both units for these missed opportunity include being divorced (15.4\%), being postmenopausal $(7.7 \%)$, need for a child $(46.1 \%)$, not informed of FP (15.4\%) and no reason $(15.4 \%)$. Previous studies had reported fear of adverse effects (40.7\%), future desire for more children (29.7\%), religious prohibition $(22.0 \%)$, cultural beliefs (24.6\%), and partner disapproval (35.6\%) as reasons for non-use of contraception [14]. Another study reported desire for more children (29\%), health concern about using contraception (25.7\%) and lack of knowledge about FP $(25.1 \%)$ as reasons for non use of FP [29]. The present reasons were stated despite the counselling rate of $12.5 \%-60 \%$ and an awareness level of between 70 $87 \%$ on FP methods and the importance of spacing. Nevertheless it should be noted that while $88 \%$ of OF providers reported that they offered counselling on FP only an average of $36 \%$ of OF clients reported being counselled on FP. This discrepancy is slightly higher than previously reported [30].

This further brings to question the quality of the counselling. Actual client centred counselling are expected to produce better results. Another study had reported $84 \%$ missed opportunity for FP counselling after visits to general practitioners [27].

Suggestions for reduction of FP missed opportunity by $\mathrm{OF}$ clients include health education and immediate post operative FP service provision after healing. Health education in this wise include all forms of awareness creation and sensitization reaching all stakeholders.

\section{Relevance of the Findings: Implications for Clinicians and Policy Makers}

Considering the high number of OF cases occurring annually, the OF units are key points that provides opportunity for FP services and information to women. Failure to do this is a missed opportunity that should be addressed by in-service training of $\mathrm{OF}$ providers, adherence to service protocol and strengthened reproductive health commodity security.

The magnitude of missed opportunity raises a lot of question on the quality of counselling and compliance to referral advices by the OF clients which requires immediate and pragmatic approach. Thus program planners need to include training skill on FP service provision in existing training package for OF service providers and ensure balanced counselling in line with the service protocol [31]. There is also the need to ensure full implementation of the free FP services in the public sector in the face of the reported out-of-pocket payments for related consumables by clients.

\section{Unanswered Questions and Future Research}

Some grey areas which may require further elucidation include the poor attitude of clients to FP especially in Sokoto and the quality of FP services and information being presently provided in these units. There is the need to establish what will motivate more health workers to the OF units and possible impact of the proposed additional workload on these health workers if having to provide integrated reproductive health services. Also it is necessary to know if the provision of information, education and communication (IEC) materials to reinforce the counselling sessions will improve FP utilization.

\section{Conclusions}

The prevalence of missed opportunity for FP uptake by OF clients has been on the increase most especially in Sokoto. This requires innovative approach like the provision of integrated reproductive health service, improved client counselling reinforced with culturally appropriate IEC materials and improved training package for OF service providers which will reduce the unmet need in the States.

\section{Limitations}

The study was limited by the poor data storage in the units, difficulty in tracing OF clients after discharge due to incomplete contact address and unwillingness of health workers to work in OF units. Also three medical doctors in the two units were not available for the study. All these account for the small sample size of the study. Initial study sites were three, with one OF unit dropped due to poor recording of clients' information which could not clearly distinguish between OF clients and the regular FP clinic clients. 
Women's Health Science Journal

The application of the questionnaire was limited to those OF clients still residing in the units or came for follow-up during the study period. Other limitations were the inability by interviewees to accurately recall past events and lack of funding to include other OF units in the Country.

Also the information provided by the OF service provider and their clients were few, but this gives credence to the findings and conclusions of the study. Nevertheless, these three information sources strengthened the inference.

It should be noted that although the FP registers did not distinguish between OF clients and non-OF clients, but the former were identified by the OF service providers using their own unit register corroborated with their institutional memory.

\section{Acknowledgment}

We appreciate the support and commitment of staff at the two OF units for sorting out the records from the archives, the OF clients for granting the interview, UNFPA office for the internet access to retrieve relevant information and our dearest family for the time devoted to this study at their expense.

\section{Disclosure Statement}

Beyond professional interest for the service of humanity, the authors have no special interest in the fistula units and FP commodities. The study was self funded by the authors only.

\section{Authors' contributions}

A-A conceived and prepared the paper. H-I collected the data from Sokoto and reviewed the final paper. I-A$\mathrm{N}$ searched the references on internet and typed the final submission. G-C-U is the internal peer reviewer of the paper. All authors read and approved the final manuscript.

\section{References}

1. United Nations (2016) Sustainable Development Goals Reports 2016. Leaving no one behind [Internet; cited 2016 December 21].

2. United Nations Population Fund, Family planning [Internet; cited 2017 January 24].

3. Moore Z, Pfitzer A, Gubin R, Charurat E, Elliott L, Croft $\mathrm{T}$ (2015) Missed opportunities for family planning: an analysis of pregnancy risk and contraceptive method use among postpartum women in 21 low-and middle-income countries. Contraception 92(1): 31-39.

4. National Population Commission (2014) Federal Republic of Nigeria, Abuja, Nigeria. Nigeria Demographic and Health Survey 2013. ICF International pp: 565.

5. London Summit on Family Planning: Summaries of commitments. Nigeria pp: 23 [Internet; cited 2016 Dec 31].

6. Danmusa S. Costed implementation plans in Nigeria, health policy plus project.

7. Osotimehin B (2013) Obstetric fistula: ending the health and human rights tragedy. The Lancet 381(9879): 1702-1703.

8. Federal Government of Nigeria (2012) Federal Ministry of Health. National strategic frame work for elimination of obstetric fistula in Nigeria 20112015. Abuja: Federal Ministry of Health pp: 82.

9. International Women's Health Program. Obstetric Fistula, A labour of loss.

10. Osotimehin B (2013) Let us end fistula in our lifetime. The Huffington Post [Internet; cited 2015 Aug 19].

11. Medical World Nigeria [Internet; cited 2016 Aug $14]$.

12. Caro D, Farrell B, Landry E, Alalade E (2013) Integrating family planning into fistula services: An evaluation and case study. Fistula Care [Internet; cited 2016 Aug 14].

13. Ngongo C (2014) Family Planning for All: The importance of contraceptive access and choice following fistula repair. Champions4Choice. Engender Health [Internet; cited 2015 Aug 19].

14. Lawani LO, Iyoke CA, Ezeonu PO (2015) Contraceptive practice after surgical repair of obstetric fistula in southeast Nigeria. Int J Gynaecol Obstet 129(3): 256-259.

15. Khisa W, Wakasiaka S, Kagema F, Omoni G (2012) Contraception knowledge and practice among fistula patients at referral centers in Kenya. International Journal of Gynecology \& Obstetrics 118(3): 220-222.

16. Stack Exchange (2017) English language and usage [Internet; cited 2017 Jan 22]. 


\section{Women's Health Science Journal}

17. Matsamura EK (2004) Uganda's fistula patients lack knowledge of prevention and treatment. Population Reference Bureau [Internet; cited 2015 Aug 19].

18. Hausa Encyclopedia.com. Encyclopedia of world cultures [Internet; cited 2016 Nov 20].

19. Encyclopedia.com. Nigeria [internet]. Worldmark encyclopedia of nations 2007 [Internet; cited 2016 Nov 20].

20. UNESCO (2012) High level international round table on literacy "Reaching the 2015 literacy target: delivering on the promise". Action plan Nigeria, pp: 25 [Internet; cited 2016 Nov 20].

21. Nigeria Distance (2016).

22. USAID Nigeria. Fistula Care plus 2007-2016 [Internet; cited 2016 December 21].

23. Ruminjo JK, Frajzyngier V, Abdullahi MB, Asiimwe F, Barry TH, et al. (2014) Clinical procedures and practices used in the perioperative treatment of female genital fistula during a prospective cohort study. BMC pregnancy Childbirth 14: 220 [Internet; cited 2016 December 21].

24. Measure Evaluation. Family Planning and Reproductive Health Indicators Database. Percent of women who have been treated for obstetric fistula who receive reintegration services [Internet; cited 2016 Aug 14].
25. Johnson KA, Turan JM, Hailemariam L, Mengsteab E Jena D, et al. (2010) The role of counselling for obstetric fistula patients: lessons learned from Eritrea. Patient Educ Couns 80(2): 262-265.

26. Fistula Care. Family planning for women and couples following fistula repair [Internet; cited 2016 Aug 14].

27. Primary Health Care Initiative (2004). Unmet Need and Missed Opportunities For Family Planning Among Married Women 15-49 Years Users of $\mathrm{MoH}$ Health Centers, pp: 131 [Internet; cited 2017 Jan 02].

28. Engender Health/Fistula Care (2012) A Training Curriculum: Counselling the obstetric fistula client, pp: 344 [Internet; cited 2016 Aug 14]

29. Strengthening Health Outcomes through the Private Sector (2016). Improving the quality and sustainability of private sector family planning and maternal and child health services in Nigeria.

30. Pranita A, Priya N, Anurag M, Lisa C, Meenakshi J, et al. Family Planning use and missed opportunities for service provision in urban Uttar Pradesh, India [Internet; cited 2017 Jan 22].

31. Federal Ministry of Health, Nigeria. National Family Planning / Reproductive Health Service Protocol. Nigeria: 2010 Revised edition. 